\title{
Cerebral aneurysms associated with human immunodeficiency virus in adults: literature review and new perspectives
}

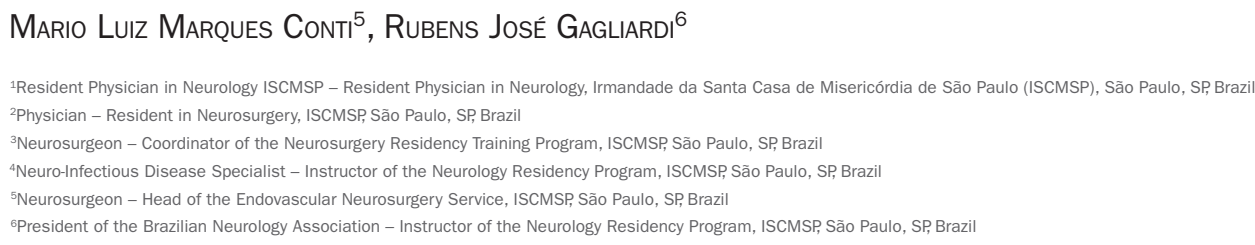

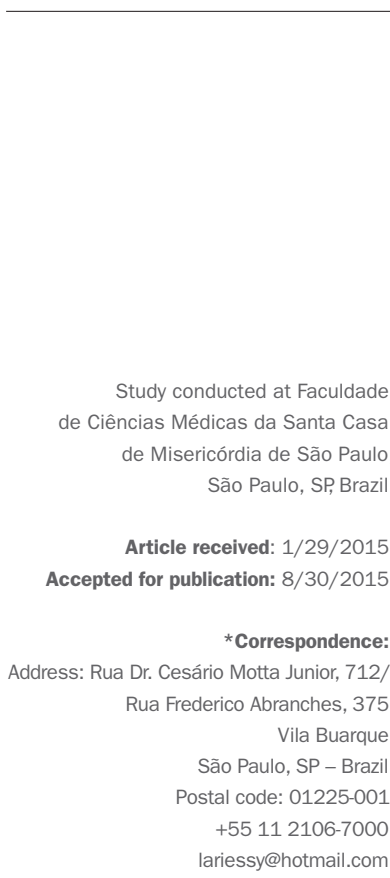

http://dx.doi.org/10.1590/1806-9282.62.01.85

\section{SUMMARY}

Introduction: the treatment of human immunodeficiency virus (HIV) infection has been decreasing patient morbidity and mortality by opportunistic infections and, thus, survival has increased. This new reality has been changing the spectrum of diseases affecting such patients.

Objective: to discuss the association between HIV and the emergence of aneurysmal brain injuries.

Method: it was performed a literature review using medical database. The following descriptors were searched: "Intracranial Aneurysms and HIV", "Intracranial Aneurysms and Acquired Immunodeficiency Syndrome," "aneurysm and brain and HIV".

Results: after performed a literature review, it was observed that the relationship between HIV infection and the formation of aneurysms appears to be real, however, it still lacks data to confirm the pathophysiology of this condition and its best treatment.

Conclusion: there are new signs and symptoms that should be studied and researched relating HIV with other changes not previously known.

Keywords: HIV, acquired immunodeficiency syndrome, intracranial aneurysm.

\section{INTRODUCTION}

Infection by human immunodeficiency virus (HIV) is a relatively new clinical entity, being first described in the 1980s. Over the years, there have always been new perspectives coming up along with better control of this infection and early diagnosis. In this article, we deal with one of the cerebrovascular changes that may be related with $\mathrm{HIV}$, which is brain aneurysm.

The relationship between cerebral aneurysms (CA) and patients with HIV infection has already been described in children since the $1980 \mathrm{~s},{ }^{1}$ having only been described in adults for a couple of years. ${ }^{2}$ In pathological autopsy studies done in children with HIV, the presence of multiple aneurysm dilatations affecting the arteries of the Willis Polygon was demonstrated, with fibrosis of the medial layer of the arteries, loss of muscle layer, destruction of the internal elastic lamina and intimae hyperplasia. ${ }^{3}$ There are several changes that might cause cerebral aneurysm; however, this article will limit itself to assess the relationship between brain aneurysm and HIV.

In patients with acquired immunodeficiency syndrome (AIDS), neurological symptoms are mainly due to the occurrence of opportunistic infections, such as infection by varicella zoster virus, cytomegalovirus (CMV), tuberculosis, toxoplasmosis and cryptococcosis. ${ }^{3}$ Neurological involvement due to the presence of CAs is rare. Most often, the CAs are asymptomatic. However, they may manifest as intracranial bleeding, thromboembolic phenomena or even with compressive brain structures symptoms. The pathophysiology of cerebral aneurysms and their association with HIV infection remains uncertain and requires further investigation. 
The objective of this paper is to review the available literature and to confirm if there are new paradigms that relate the presence of HIV infection with the formation of cerebral aneurysms, how they are being treated and what are the possible theories for the pathophysiology of this clinical entity.

\section{Method}

This article is a literature review. A bibliographical research was made in October 2013 in MEDLINE, Rev ${ }^{\circledR}$ and PubMed ${ }^{\circledR}$ databases using the following descriptors: "Intracranial Aneurysms and HIV", "Intracranial Aneurysms and Acquired Immunodeficiency Syndrome," "aneurysm and brain and HIV," with no specified date range for publication of articles.

In the initial research, 87 articles that included the descriptors above, including case reports and literature reviews, were found. Out of the total, those which were not in Portuguese, English or French were excluded. Thus, 17 articles were selected to compose the references of this review.

\section{Discussion}

Neurological disease is commonly associated with HIV infection and may result from infection of the central nervous system (CNS), cancer, dementia, myelopathy, sensory neuropathy or myopathy. Cerebrovascular disease is also described in association with HIV, but it is not thoroughly understood. ${ }^{4}$ Since the first reports of AIDS in homosexual men in San Francisco, USA, in 1981, HIV has been associated with the pathogenesis of vascular diseases. The South African experience of HIV-related aneurysms in infected young individuals suggests a distinct clinical and pathological entity based on its distribution, morphological description and histopathological findings. ${ }^{5}$ The virus is associated with morphological changes that could increase the risk of these neurological diseases.

The aneurysmal vasculopathy that occurs in association with HIV infection is usually related with fusiform dilatation (Figure 1), occurs in young adults, and affects predominantly extracranial vessels. Intracranial aneurysms represent infrequent finding, being generally described in children. ${ }^{4}$ There are some reports in the literature correlating the severity of HIV infection as demonstrated by CD4 counts and the presence of intracerebral aneurysms. ${ }^{4}$ However, some authors have questioned this association. ${ }^{6}$

The prevalence of cerebrovascular disease in pediatric HIV-infected population is only $1.3 \%$; however, this prevalence increases to $25 \%$ in autopsy studies, ${ }^{7}$ which corroborates that many of them are asymptomatic. The patho-
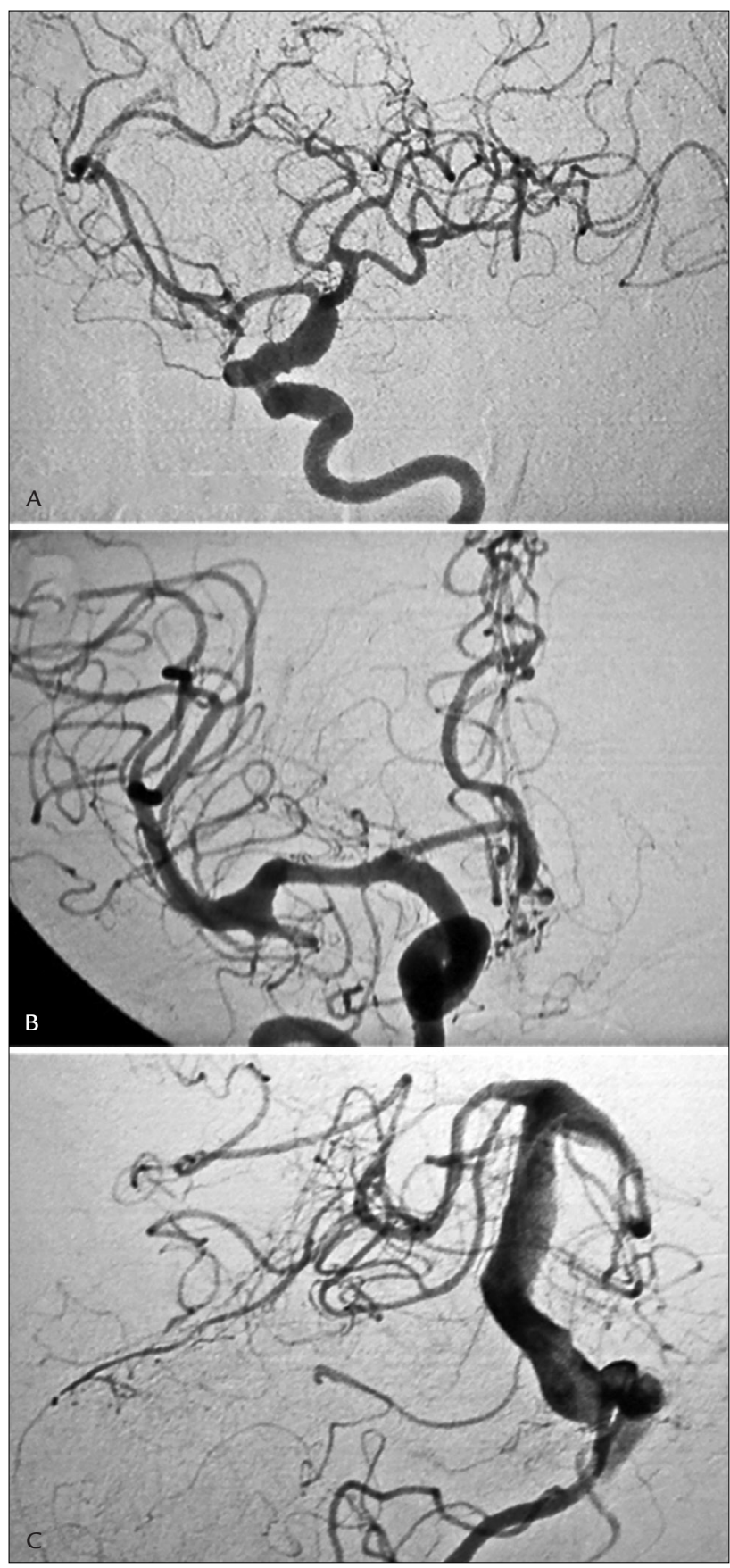

FIGURE 1 Cerebral angiography showing multiple cerebral fusiform aneurysms (A - left internal carotid artery/lateral incidence; B: right internal carotid artery/frontal incidence; C: basilar artery/ frontal incidence).

genic mechanism of aneurysmal disease associated with HIV includes hypoperfusion, cardiomyopathy, endocarditis with septic or thrombotic emboli, thrombocytopenia, and intracranial vessels infections by cytomegalovirus (CMV), varicella zoster virus, fungi or mycobacteria. ${ }^{8}$ It is known that the ratio of fusiform and saccular aneurysms 
in the pediatric population with HIV is greater than that existing in the general population, where there is a clear predominance of saccular aneurysms. ${ }^{9}$

Most authors state that the HIV-related artery is associated with chronic inflammation caused by the virus itself or by opportunistic organisms. ${ }^{6,8}$ The first description of the association between cerebral aneurysm and HIV infection in 1989 occurred in two patients from Zimbabwe and in one from the United States of America (USA). ${ }^{10}$

Dubrovsky et al. ${ }^{8}$ in a study published in 1998 reported five pediatric cases, and reviewed the literature about eight new cases of children with cerebral aneurysm and AIDS. In four of these cases, post-mortem studies were performed, and all patients had ectasia and aneurysm restricted to the large arteries of the circle of Willis. The histopathological findings were of intimae thickening, destruction of internal elastic lamina, loss of muscle lay$\mathrm{er}$, and fibrosis of the medial arterial layer.

In adults, the histopathology of cerebral aneurysms associated with HIV demonstrates luminal thrombosis and fibrosis with concentric hyalinization of the intima layer, atrophy of the medial, thickening and fragmentation of the elastic lamina. These conditions cause ectasia of the intracranial vessels. Furthermore, there is a luminal surface neutrophil infiltration related to thrombus. ${ }^{11}$ For Tipping et al., ${ }^{11}$ it is not possible to visualize the aneurysmal wall in HIV research and the research of the HIV p24 antigen in the vessels is negative. However, in a case reported by Teo et al. ${ }^{12}$ in 2013, the presence of the HIV glycoprotein 41 was described in mononuclear cells in the intima layer of intracranial arterial aneurysms. Extracranial aneurysms in patients with HIV are described as secondary to leukocytoclastic vasculitis of the vasa vasorum..$^{13}$ This association is not present in intracranial aneurysms ${ }^{11}$ and it is likely to have a different pathophysiology in the two situations.

The pathogenesis of intracranial aneurysms in HIV infections has been postulated as a result of immune activation in response to the transendothelial migration of HIV, with cerebral tropism for mononuclear cells. ${ }^{13}$ Another theory is that a change in the dynamic vascular response to pulsatile blood flow regulated by changes in circulating cytokines and growth factors would lead to vascular remodeling, causing the aneurysm. ${ }^{13}$ Opportunistic infections which are well known to involve vessels - varicella zoster virus, herpes simplex virus, CMV, Epstein-Barr virus, Treponema pallidum, Candida albicans, Cryptococcus neoformans, and Mycobacterium tuberculosis - may increase the production of cytokines and growth factors. ${ }^{14}$ Thus, repeated infections may con- tribute to an increased production of elastase, leading to thickening and fragmentation of the internal elastic lamina. ${ }^{9}, 15$ This is an early histological finding associated with development of fusiform aneurysms. ${ }^{9,16}$ Because of this association, opportunistic infections should be promptly investigated in patients with cerebral aneurysms and HIV. The use of antiretroviral therapy may lead to the emergence of immune reconstitution inflammatory syndrome (IRIS), which could lead to worsening of the vasculopathy. ${ }^{17,18}$

In this review, ${ }^{14}$ case reports of adult patients with HIV and fusiform aneurysm, ${ }^{2-4,10,17,19}$ were identified. The age of patients ranged from 23 to 43 , with a mean age of 35. ${ }^{1}$ The gender ratio showed male predominance ( 9 men and 5 women), which is also the prevalence of HIV in Brazil (1.7 men for every woman infected). CD4 counts ranged from $<1$ to 496 cells $/ \mathrm{mm}^{3}$ and viral load (VL) was described in only 6 of the 14 reports. This was described as being from undetectable to up to $1,107,818$ copies $/ \mathrm{mL}$. Affected patients had miscellaneous neurological condition, presenting from transitory ischemic attack (TIA) to mental confusion with meningeal signs as can be seen in Table 1.

There is still a big gap to determine the best treatment for this probable new clinical entity which some authors refer to as vasculopathy with cerebral aneurysms (VCA),${ }^{10,20}$ in patients with HIV. This is largely due to the fact that an exact pathophysiology for the formation of such vascular changes has not been determined. However, in the literature, there are reports that the use of antiretroviral therapy (ART), on account of severe immunosuppression, is an acceptable behavior. There is no evidence in the literature regarding the best ART for these cases, but some data must be taken into account in order to choose the best treatment. This includes antiretroviral drugs that have greater CNS penetration, such as zidovudine, lopinavir/ritonavir and nevirapine, the genotype of the virus, and tolerability and toxicity of the therapy in question..$^{2,21}$ There are reports of the use of corticosteroids, such as dexamethasone, metiprednisolone, prednisone and decortine. ${ }^{2,22}$ However, the mechanism of action of these drugs in aneurysm vasculopathy is still uncertain, largely because the mechanism of formation of the vasculopathy is still unknown.

Given the rarity of fusiform aneurysms, some authors suggest that, in their presence, whether in children or adults, investigation for possible HIV infection should be done. ${ }^{2,23}$ Such conduct is justified by the idea that the presence of fusiform malformations may already represent some degree of immunodeficiency. ${ }^{2}$ 
TABLE 1 Epidemiological profile of case reports.

\begin{tabular}{|c|c|c|c|}
\hline Author & Age/Gender & Neurological presentation & CD4/VL \\
\hline Goldstein & 38 years/ $\mathrm{F}$ & Hemiparesis & $<1 / 79,074$ \\
\hline \multirow[t]{3}{*}{ Modi } & 37years/ M & Severe cognitive alteration & $164 /-$ \\
\hline & 43 years/ $M$ & Headache/mental confusion/meningism & $172 /-$ \\
\hline & 43 years/ $M$ & Convulsion & $17 /-$ \\
\hline Hamilton & 34 years/ $M$ & Headache/fever/hemiparesis & 66/undetectable \\
\hline Ake & 29 years/ $F$ & Disorders of language and cognition & $15 / 191,429$ \\
\hline Tipping & 27 years/ $F$ & Hemiparesis & $14 /-$ \\
\hline \multirow[t]{2}{*}{ Kossorotoff } & 23 years/ $M$ & Recurrent $\mathrm{ACM}$ stroke & $496 /$ \\
\hline & 32 years/ $M$ & Chronic headache & 338 \\
\hline O'Charoen & 36 years/ $M$ & Dysarthria/paresis & $43 / 298,000$ \\
\hline \multirow[t]{2}{*}{ Berkefeld } & 37 years/ $M$ & Hemiparesis progressive/change in the visual field recurrent TIA/aphasia/ & - \\
\hline & 31 years/ $M$ & hemiparesis & - \\
\hline Benjilali & 39 years/ $F$ & Headache/fever/dizziness/tinnitus & $82 / 40,783$ \\
\hline Sanada & 43 years/ $F$ & Fever/stupor/hemiplegia & $12 / 1,107,818$ \\
\hline
\end{tabular}

\section{Conclusion}

There is a clear correlation between the presence of intracranial fusiform aneurysms and HIV infection. A review of the current literature does not allow a conclusion about the pathophysiology of this association. Thus, further research should be conducted to determine concretely the mechanisms involved in the intracranial vascular alterations caused by HIV. Autopsy studies may be useful to determine the correct incidence of this association. The actual incidence is underestimated because, in many cases, patients are asymptomatic.

\section{Resumo}

Aneurismas cerebrais associados ao vírus da imunodeficiência humana em adultos: revisão da literatura e novas perspectivas

Introdução: o tratamento da infecção pelo vírus da imunodeficiência humana (HIV) tem diminuído a morbidade e mortalidade por infecções oportunistas nesses pacientes e, portanto, aumentado a sobrevida. Essa nova realidade tem mudado o espectro de doenças que afetam esses pacientes.

Objetivo: discutir a associação entre HIV e ocorrência de aneurismas cerebrais.

Método: foi realizada revisão da literatura utilizando bancos de dados médicos. Foram pesquisados os seguintes descritores: "HIV e aneurismas intracranianos", "aneurismas intracranianos e síndrome da imunodeficiência adquirida”, aneurismas, cérebro e HIV.
Resultados: a relação entre a infecção pelo HIV e a formação de aneurismas parece ser real; porém, ainda faltam dados que confirmem a fisiopatologia dessa condição e seu melhor tratamento.

Conclusão: existem novos sinais e sintomas, que devem ser estudados e pesquisados, relacionando o HIV com outras alterações previamente desconhecidas.

Palavras-chave: HIV, síndrome de imunodeficiência adquirida, aneurisma intracraniano.

\section{References}

1. Kure K, Park YD, Kim TS, Lyman WD, Lantos G, Cho S, et al. Immunohistochemical localization of an HIV epitope in cerebral aneurysmal arteriopathy in pediatric acquired immunodeficiency syndrome (AIDS). Pediatr Pathol. 1989; 9(6):655-67.

2. Goldstein DA, Timpone J, Cupps TR. HIV-associated intracranial aneurysmal vasculopathy in adults. J Rheumatol. 2010; 37(2):226-33.

3. O'Charoen P, Hesselink JR, Healy JF. Cerebral aneurysmal arteriopathy in an adult patient with acquired immunodeficiency syndrome. AJNR Am J Neuroradiol. 2007; 28(5):938-9.

4. Modi G, Ranchod K, Modi M, Mochan A. Human immunodeficiency virus associated intracranial aneurysms: report of three adult patients with an overview of the literature. J Neurol Neurosurg Psychiatry. 2008; 79(1):44-6

5. Naidoo NG, Beningfield SJ. Other manifestations of HIV vasculopathy. S Afr J Surg. 2009; 47(2):46-53.

6. Statler JD, Slaughter CR, Ronsivalle JA. Human immunodeficiency virus arteriopathy of the adult cerebral circulation. Mil Med. 2007; 172(6):647-9

7. Neto AC, Bruck I, Coelho LOM, Cruz CR da, Liu CB, Gomes AF, et al. Aneurisma de artéria cerebral em criança com síndrome da imunodeficiência adquirida. Arq Neuropsiquiatr. 2001; 59(2B):444-8.

8. Dubrovsky T, Curless R, Scott G, Chaneles M, Post MJ, Altman N, et al. Cerebral aneurysmal arteriopathy in childhood AIDS. Neurology. 1998; 51(2):560-5.

9. Bulsara KR, Raja A, Owen J. HIV and cerebral aneurysms. Neurosurg Rev $2005 ; 28(2): 92-5$ 
10. Kossorotoff M, Touzé E, Godon-Hardy S, Serre I, Mateus C, Mas JL, et al. Cerebral vasculopathy with aneurysm formation in HIV-infected young adults. Neurology. 2006; 66(7):1121-2.

11. Tipping B, de Villiers L, Candy S, Wainwright H. Stroke caused by HIVassociated intracranial large-vessel aneurysmal vasculopathy. Arch Neurol 2006; 63(11):1640-2.

12. Teo L, Venkatesh S, Ho K. Clinics in diagnostic imaging. Singapore Med J. 2007; 43(7):377-80.

13. Chetty R, Batitang S, Nair R. Large artery vasculopathy in HIV-positive patients: another vasculitic enigma. Hum Pathol. 2000; 31(3):374-9.

14. Mazzoni P, Chiriboga CA, Millar WS, Rogers A. Intracerebral aneurysms in human immunodeficiency virus infection: case report and literature review. Pediatr Neurol. 2000; 23(3):252-5.

15. Connor MD, Lammie GA, Bell JE, Warlow CP, Simmonds P, Brettle RD. Cerebral infarction in adult AIDS patients: observations from the Edinburgh HIV Autopsy Cohort. Stroke. 2000; 31(9):2117-26.

16. Shah SS, Zimmerman RA, Rorke LB, Vezina LG. Cerebrovascular complications of HIV in children. AJNR. 1996; 17(10):1913-7.
17. Krizanac-Bengez L, Mayberg MR, Janigro D. The cerebral vasculature as a therapeutic target for neurological disorders and the role of shear stress in vascular homeostatis and pathophysiology. Neurol Res. 2004; 26(8):846-53

18. Bonkowsky J, Pavia A. Cerebral vasculopathy with aneurysm formation in HIV infected young adults. Neurology. 2007; 68(8):623.

19. Hamilton DK, Kassell NF, Jensen ME, Dumont AS. Subarachnoid hemorrhage and diffuse vasculopathy in an adult infected with HIV. J Neurosurg. 2007; 106(3):478-80.

20. Benjilali L, Zahlane M, Essaadouni L. Intracranial aneurysm revealing a HIV infection and resolving with highly active antiretroviral therapy. Neurol India. 2012; 60(3):351-3.

21. Sanada M, Koizumi Y, Hodohara K, Kawai H. Multiple cerebral aneurysms caused by HIV-associated vasculopathy. Intern Med. 2010; 49(18):2029-30.

22. Berkefeld J, Enzensberger W, Lanfermann H. MRI in human immunodeficiency virus-associated cerebral vasculitis. Neuroradiology. 2000; 42(7):526-8.

23. Ake JA, Erickson JC, Lowry KJ. Cerebral aneurysmal arteriopathy associated with HIV infection in an adult. Clin Infect Dis. 2006; 43(5):e46-50. 